\title{
Seed-specific expression of truncated $O S G A D 2$ produces GABA-enriched rice grains that influence a decrease in blood pressure in spontaneously hypertensive rats
}

\author{
Kazuhito Akama · Junko Kanetou • \\ Shunsuke Shimosaki · Kouhei Kawakami · \\ Satoru Tsuchikura $\cdot$ Fumio Takaiwa
}

Received: 7 January 2009/Accepted: 17 April 2009/Published online: 12 May 2009

(C) The Author(s) 2009. This article is published with open access at Springerlink.com

\begin{abstract}
Gamma-aminobutyric acid (GABA) is a four-carbon amino acid that is commonly present in living organisms and functions as a major inhibitory neurotransmitter in mammals. It is understood to have a potentially anti-hypertensive effect in mammals. GABA is synthesized from glutamate by glutamate decarboxylase (GAD). In plants, GAD is regulated via its calmodulin-binding domain (CaMBD) by $\mathrm{Ca}^{2+} / \mathrm{CaM}$. We have previously reported that a C-terminal truncated version of one of the five rice $\mathrm{GAD}$ isoforms, GAD2 $\Delta \mathrm{C}$, revealed higher enzymatic
\end{abstract}

Electronic supplementary material The online version of this article (doi:10.1007/s11248-009-9272-1) contains supplementary material, which is available to authorized users.

K. Akama $(\varangle) \cdot$ J. Kanetou

Department of Biological Science, Shimane University, Nishikawatsu 1060, Matsue, Shimane 690-8504, Japan e-mail: akama@life.shimane-u.ac.jp

S. Shimosaki · K. Kawakami

Department of Experimental Animals, Center

for Integrated Research in Science, Shimane University,

Izumo, Shimane 693-8501, Japan

S. Tsuchikura

Disease Model Cooperative Research Association,

Hamamatsu, Shizuoka 433-8114, Japan

F. Takaiwa

Transgenic Crop Research and Development Center, National Institute of Agrobiological Sciences, Kannondai 2-1-2, Tsukuba, Ibaraki 305-8602, Japan activity in vitro and that its over-expression resulted in exceptionally high GABA accumulation (Akama and Takaiwa, J Exp Bot 58:2699-2607, 2007). In this study, $G A D 2 \triangle C$, under the control of the rice glutelin promoter (GluB-1), was introduced into rice cells via Agrobacterium-mediated transformation to produce transgenic rice lines. Analysis of the free amino acid content of rice grains revealed up to about a 30-fold higher level of GABA than in non-transformed rice grains. There were also very high levels of various free protein amino acids in the seeds. GABA-enriched rice grains were milled to a fine powder for oral administration to spontaneously hypertensive rats (SHRs) and normotensive WistarKyoto rats (WKYs). Six weeks of administration showed that transgenic rice brings about a $20 \mathrm{mmHg}$ decrease in blood pressure in two different kinds of SHRs, while there was no significant hypotensive effect in WKYs. These results suggest an alternative way to control and/or cure hypertension in humans with GABA-enriched rice as part of a common daily diet.

Keywords GABA $\cdot \gamma$-Aminobutyric acid . Glutelin promoter - Glutamate decarboxylase . Hypertension - Transgenic rice

\section{Introduction}

Hypertension is respected as one of the most critical risk factors accompanying severe diseases: when it is 
left untreated for a long period of time, the risk of other cardiovascular diseases will undoubtedly increase. About one billion people are now suffering from hypertension and it is expected to increase $60 \%$ by 2,025 worldwide (Kearney et al. 2005). Patients with severe hypertension have to depend upon various kinds of blood pressure-lowering drugs such as angiotensin converting enzyme (ACE) inhibitors, calcium channel blockers, diuretics and others, whose costs are increasing in ratio to total expenses of drugs each year.

Foods or diets that contain bioactive substances with anti-hypertensive effects have received more attention to date. For example, some natural peptides detected in many different kinds of foods such as egg, fish protein and milk (review, Hong et al. 2008) have ACE inhibitory potential.

Recently, $\gamma$-aminobutyric acid (GABA) has received attention as a healthy functional compound: GABA itself, a non-protein amino acid, is ubiquitously present in organisms ranging from bacteria to higher organisms like rice and humans. In mammals, GABA is distributed mainly in the brain and is known to function as a major inhibitory neurotransmitter in the central nervous system (Curtis and Johston 1974). Administration of GABA reportedly lowers blood pressure in experimental animals (Takahashi et al. 1955), and GABA-enriched products have been found to have hypotensive effects in Dahl saltsensitive rats and spontaneously hypertensive rats (SHRs) (Abe et al. 1995; Hayakawa et al. 2004), in addition to improving brain function in senescent monkeys (Leventhal et al. 2003).

GABA is produced from glutamate via decarboxylation by glutamate decarboxylase (GAD) in the cells. Interestingly, plant GAD generally contains an extended region (about 30 amino acids long) at the C-terminus, called the calmodulin-binding domain (CaMBD), which plays a vital role in the regulation of GAD activity in vitro and in vivo (Bouché and Fromm 2004). Baum et al. (1996) analyzed the function of the CaMBD in vivo and found that overexpression of petunia GAD lacking a CaMBD in transgenic tobacco resulted in increased amounts of GABA in plant cells, but lower levels of glutamate, implying that the CaMBD plays a role in autoinhibition.

Data from the rice genome project show that there exist five $G A D$ genes in the rice (Project IRGS 2005).
OsGAD2 that is encoded in one of these genes is not able to bind to $\mathrm{Ca}^{2+} / \mathrm{CaM}$ (Akama et al. 2001). But that truncation of the $\mathrm{C}$-terminal peptide confers higher enzymatic activity both in vitro and in vivo on OsGAD2, and over-expression of this enzyme resulted in an extremely large amount of GABA to be accumulated in cells (Akama and Takaiwa 2007). However, the plants that regenerated from callus cells that expressed this mutant gene (i.e., a truncated form of $O s G A D 2, O s G A D 2 \triangle C$ ) had aberrant phenotypes (dwarfism and pale green leaves) and were infertile, so there was no way to evaluate the GABA content of the next generation of the seeds. In this study, in order to avoid this situation, we used a rice storage protein promoter, the glutelin promoter $(G l u B-1)$, to obtain endosperm-specific expression of $O s G A D 2 \triangle C$ in order to increase the amount of GABA in the rice grain. As a result, high levels of GABA in rice grains were detected. The GABA-enriched milled rice was used for evaluating changes in blood pressure of SHRs.

\section{Materials and methods}

Vector construction and rice transformation

Truncated $O s G A D 2$ cDNA, designated $O s G A D 2 \triangle C$, in which the $3^{\prime}$-proximal region coding for the 31 C-terminal amino acids was removed, was subcloned into the Ti plasmid pCAMBIA1302 (Akama and Takaiwa 2007). This truncated GAD gene was placed under the control of the constitutive cauliflower mosaic virus (CaMV) $35 \mathrm{~S}$ promoter and its terminator. In order to obtain seed-specific expression in rice plants, the CaMV $35 \mathrm{~S}$ promoter was replaced with the rice glutelin promoter $(G l u B-1)$ (Takaiwa et al. 1991): a $2.3 \mathrm{~kb} X b a \mathrm{I} / \mathrm{NcoI}$ fragment of GluB-1 DNA was first cloned into pUC18, then after removal of the CaMV $35 \mathrm{~S}$ promoter from the Ti plasmid, the resulting DNA fragment was subcloned into the relevant site of the Ti plasmid, yielding GluB-1::GAD2 $\triangle C$ in pCAMBIA (Fig. 1a). The vector was introduced into Agrobacterium strain EHA105 (Hood et al. 1993). Transformation of rice calli via Agrobacterium and subsequent regeneration were performed as described in Hiei et al. (1994). 
A

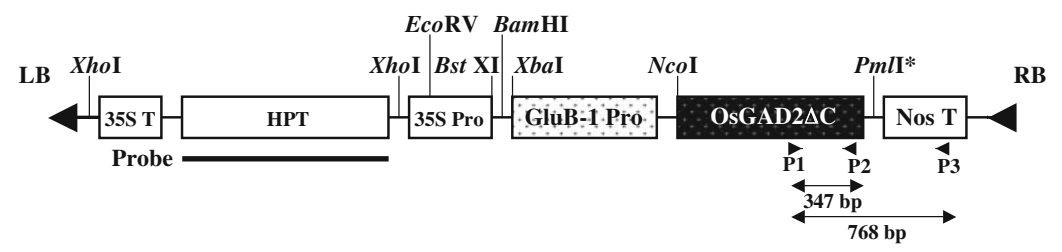

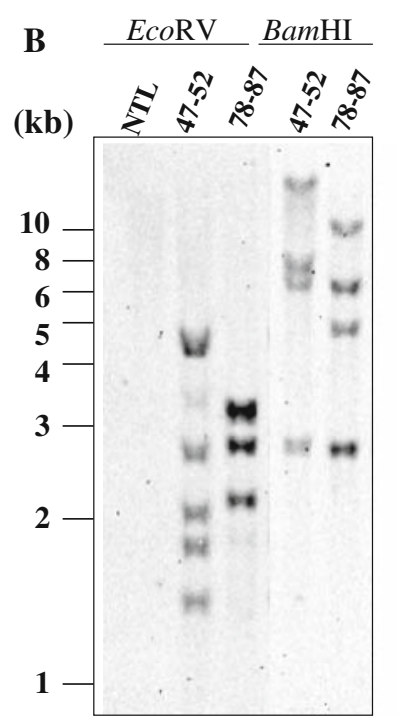

Fig. 1 T-DNA constructs used for rice transformation and molecular analysis of rice plants. a A 2.3-kb XbaI/NcoI fragment of the rice glutelin promoter $(G l u B-1)$ gene was cloned upstream of $O s G A D 2 \triangle C$ (Akama and Takaiwa 2007) in the T-DNA of pCAMBIA1302 (CAMBIA). A Ti plasmid carrying this T-DNA construct was introduced into Agrobacterium strain EHA105. GluB-1 Pro, 2.3-kb rice glutelin GluB-1 promoter; Nos T, nopaline synthase gene terminator; HPT, hygromycin phosphotransferase gene; 35S T, CaMV 35S terminator; LB, left border; RB, right border. Restriction enzyme sites are indicated by a line. The asterisk next to PmlI indicates that this site was used for cloning after cleavage with this enzyme followed by fill-in of the sticky end. Thick line corresponds to a hybridization probe for Southern blot analysis. Arrowheads indicate regions of PCR primers. Expected sizes of DNA fragment by PCR are shown between primers. b Southern blot analysis of the transgenes. Plant DNA was

Plant materials and growth conditions

Oryza sativa L. cv. Nipponbare was used in this study. Rice seeds were sterilized, germinated and grown in a growth-chamber as described by Akama et al. (2001). Shoots that regenerated after plant transformation (described below) were transferred to artificial soil (Bonsol; Sumitomo Chemical Co. Ltd, Osaka, Japan) and were grown for about 2 months, at which time seeds were harvested. Rice plants of $\mathrm{T}_{0}, \mathrm{~T}_{1}$ and $\mathrm{T}_{2}$ generations after self-pollination were digested with BamHI or EcoRV and transferred to a membrane. HPT-specific probe was PCR-amplified from Ti plasmid vector in the presence of digoxigenin-dUTP, hybridized with the membrane, and washed under stringent conditions. Plant DNAs are NTL: non-transformed line, line 47-52, line 78-87, as indicated above each lane. Positions of DNA ladder marker are showed on the left side. c PCR analysis of transgenes. After PCR amplification, DNA samples were fractionated on a $2 \%$ agarose gel. Template DNAs were shown above each lane. Primer combinations were $\mathrm{P} 1 \times \mathrm{P} 2$ and $\mathrm{P} 1 \times \mathrm{P} 3$ for four left lanes and four right lanes, respectively. Positions of DNA ladder marker are shown on the left side. An arrow indicates an intron-containing fragment (644 bp in length) amplified from the authentic GAD2 gene in the rice genome. Control indicates the Ti plasmid that was used for rice transformation in this study

cultivated in plant growth chambers $\left(26^{\circ} \mathrm{C}\right.$ with $12 \mathrm{~h}$ [light] and $12 \mathrm{~h}$ [dark]). In order to harvest a sufficient quantity of rice grains in the $T_{3}$ plants for milling and administration to the rats, seedlings were planted in large pots $(25 \mathrm{~cm}$ in diameter) containing soil in a non-contained greenhouse ( $40 \mathrm{~m}^{2}$ in area) in the campus of Shimane University (Matsue, Japan) under natural condition from April to September. In the cultivation of $T_{3}$ generation, several parameters for rice yield were investigated. 
Analysis of the transgene in rice $T_{1}$ plants

Total DNA was extracted from rice seedlings grown on Murashige and Skoog solid medium (Murashige and Skoog 1962) using the CTAB method (Murray and Thompson 1980). Isolated DNA was used for Southern blot analysis, essentially according to Akama et al. (2001). DNA probe (800 bp in length) was PCRlabeled with a digoxigenin-UTP as a template for hygromycin phosphotransferase (HPT) gene using the primers $5^{\prime}$-CGTTATGTTTATCGGCACTTT-3' and 5'-GGGCGTCGGTTTCCACTATCG- ${ }^{\prime}$ ' with cycling parameters as follows: 30 cycles at $95^{\circ} \mathrm{C}(30 \mathrm{~s}), 60^{\circ} \mathrm{C}$ (30 s) and $72^{\circ} \mathrm{C}(60 \mathrm{~s})$. In parallel, PCR analysis was performed to confirm the presence of the OsGAD2 $\triangle C$, using the plant DNAs and the Ti plasmid as templates with combination of primer set of P1 (5'-GACCAGCC AACCTTCACGCTC-3') and P2 (5'-AAGTAACCCG GACGACGACG- $\left.3^{\prime}\right)$ or P1 and P3 (5'-TTCCCGATC TAGTAACATAG- $\left.3^{\prime}\right)$ under the PCR conditions of 35 cycles at $95^{\circ} \mathrm{C}(30 \mathrm{~s}), 60^{\circ} \mathrm{C}(30 \mathrm{~s})$ and $72^{\circ} \mathrm{C}(45 \mathrm{~s})$.

Protein analysis and in situ hybridization in the $\mathrm{T}_{2}$ seeds

Total protein was extracted from $\mathrm{T}_{2}$ generation of two different fractions (milled rice fraction and bran fraction) from rice grain 4 weeks after fertilization using extraction buffer (50 mM Tris- $\mathrm{HCl}$ [pH 7.5], 5 mM EDTA, $1 \mathrm{mM}$ DTT, $1 \mathrm{mM}$ PMSF). In parallel, seeds were sampled every week between 2 and 7 weeks after flowering in order to explore expression of transgene during seed maturation at the protein level. Protein samples were separated by $12 \%$ SDS/PAGE and transferred to a membrane and western blotted using an anti-GAD2 polyclonal antibody, as described by Akama and Takaiwa (2007). Localization of protein over-expressed in the seeds was determined utilizing in situ western hybridization as described by Qu et al. (2003).

GABA and amino acid analysis

Rice grains $\left(\mathrm{T}_{2}\right.$ to $\left.\mathrm{T}_{4}\right)$ were homogenized using $8 \%$ $(\mathrm{v} / \mathrm{v})$ trichloroacetic acid (TCA). After centrifugation, the supernatant was extracted twice using diethylether to remove the remaining TCA. Quantitative determination of GABA content was performed essentially as described by Graham and Aprison
(1966). Aliquots of a sample were mixed with reaction buffer $\left(100 \mathrm{mM} \mathrm{NaPO}_{4}[\mathrm{pH} 9.0], 0.5 \mathrm{mM}\right.$ $\mathrm{NADP}^{+}, 0.6 \mathrm{mM} \alpha$-ketoglutarate, $1.2 \mathrm{mM}$ 2-mercaptoethanol, 0.005 units of GABase [SIGMA]) then incubated at $37^{\circ} \mathrm{C}$ for $1 \mathrm{~h}$. Reduction of $\mathrm{NADP}^{+}$to NAPDH during the two-step enzymatic reaction of GABA to succinate via succinic semialdehyde was detected fluorometrically using a fluorescence reader (Genios FL; TECAN, Salzburg, Austria). In parallel, the levels of some amino acids in polished rice $\left(\mathrm{T}_{4}\right)$ were determined using an automated amino acid analyzer (JLC-300; JOEL, Tokyo, Japan).

Analysis of general composition of rice $\mathrm{T}_{4}$ grains

Basic composition such as water, protein, fat, carbohydrate, and mineral and vitamin content of the grains from non-transformed Nipponbare (NT) and GABA-enriched rice was analyzed by the Food Analysis Technology Center (Osaka, Japan).

Oral administration of GABA-enriched rice $\left(\mathrm{T}_{4}\right)$ to rats

The experiment plan of the present study was approved by the Animal Experiment Committee of the Department of Experimental Animals, Center for Integrated Research in Science, Shimane University, Izumo, Japan. The entire experiment followed the guidelines issued by the committee. Three kinds of rats (all male and 8 weeks old) were used in this study. Two types were spontaneously hypertensive rats, SHR/NcrlCrlj (SHR) and SHR/NDmcr-cp (SHR/ cp) while the remaining were normotensive WistarKyoto rats (WKY). SHRs and WKYs were purchased from Charles River Japan, Inc., Yokohama, Japan. SHR/cps were kindly provided by Japan SLC, Inc., Hamamatsu, Japan. Order of animal experiments was first with SHR, second with SHR/cp and last with WKY, using transgenic rice from line 47-52 for SHR and 78-87 for SHR/cp and WKY. Rats were housed one per cage (temperature at $23 \pm 2^{\circ} \mathrm{C}$, humidity at $55 \pm 10 \%$, 7-19: light, 19-7: dark) and fed a standard diet (MF; Oriental Yeast Industry, Tokyo, Japan) and received tap water ad libitum. After 2 weeks of acclimation, rats were divided into four experimental groups ( $n=6$ rats) except for WKY. For oral administration, rice grain samples were prepared as follows: rice grains were subjected to a 
rice milling machine (KG-16, National Ltd, Kobe, Japan) and then processed to a fine powder with a blender, which was then suspended in distilled water. A 10-ml suspension of rice grain powder was equally administered and the amount of GABA in each rice sample was calculated per $1 \mathrm{~kg}$ rat fresh weight. Low dose rice containing $0.1 \mathrm{mg}$ GABA, high-dose rice containing $0.5 \mathrm{mg}$ GABA, $0.5 \mathrm{mg}$ GABA reagent and NT rice containing $0.016 \mathrm{mg}$ GABA, respectively, was administered to each corresponding group with a sonde. In the case of GABA reagent, NT milled rice powder was supplemented as an equal weight to GABA-enriched rice. An oral administration was conducted once daily continuing for 6 weeks. Once a week, the body weight and systolic blood pressure (SBP) of the rats were measured. To measure SBP, each rat was first kept at $37^{\circ} \mathrm{C}$ for $10 \mathrm{~min}$, and then SBP of each rat was determined by the tail-cuff method using a blood pressure analyzer (BP-98A, Softron, Co. Ltd, Tokyo, Japan).

Statistical analyses of data

The data were analyzed by using Student's unpaired $t$-test in the Microsoft Excel and differences were considered to be significant at $P<0.05$ or $P<0.01$.

\section{Results}

Construction of $G A D 2 \triangle C$ controlled

by a seed-specific promoter and rice transformation

A truncated $G A D 2$ gene (i.e., $G A D 2 \triangle C$ ) under the control of the GluB-1 promoter in a T-DNA region (Fig. 1a) was introduced in rice callus cells via Agrobacterium-mediated gene transfer. Out of 15 independent transgenic lines produced to be regenerated and transferred to the soil. No visible differences in the phenotypes (including fertility) of NT and transgenic rice plants were detected. Three to four weeks after flowering, rice seeds from these independent 15 plants were each subjected to GABA quantification. Determined an average GABA level of twelve grains in each plant, that of two lines was significantly higher than that of the other remaining 13 lines. Thus these lines (47-52 and 78-87) were selected for further analysis: total DNAs of $T_{1}$ plants were isolated for Southern blot analysis using the gene encoding hygromycin phosphotransferase (HPT) as a probe. Figure $1 \mathrm{~b}$ shows the presence of four to five copies of T-DNA, in the single locus: these seeds showed a ratio three resistant to one sensitive segregation in the MS media containing hygromycin (data not shown). Besides, PCR amplification with two different combinations of the primer sets strongly suggests the presence of several copies of the $G A D 2 \triangle C$ in the $\mathrm{T}_{1}$ plant genomes (Fig. 1c). In order to examine truncated $G A D 2$ expression during seed maturation, total protein was extracted from the seeds (six seeds per sample) in $\mathrm{T}_{2}$ generation harvested weekly from weeks 2 to 7 following pollination. Western blot analysis indicated a high and stable accumulation of proteins over-expressed in the seeds, while a markedly lower amount of GAD2 protein was present in the NT seeds (Fig. 2a). A strong band was unexpectedly detected between protein bands corresponding to GAD2 and GAD2 $\triangle \mathrm{C}$, respectively, in the 7 weeks of line 78-87, likely to be an artifact or nonspecific binding. As previously reported, the expression level of $O s G A D 2$ in maturing seeds is quite low (Akama et al. 2001). In two transgenic lines tested, a significant level of seed-specific expression was induced by over-expression of the GluB-1 promoter controlled $O s G A D 2 \triangle C$ during seed maturation.

Harvest of rice $T_{4}$ grains in greenhouse

The number of pots for lines $47-52$ and $87-78$ to be cultivated were 35 and 87 in the greenhouse, respectively. After 1 month of self-pollination, seeds were harvested to pool each line. Final yields (brown grain) were $1.13 \mathrm{~kg}(47-52)$ and $3.59 \mathrm{~kg}$ (78-87). Table S1 shows yield components of the nontransformed line (NTL) and two transgenic lines. There was no significant difference in agricultural traits examined between NTL and transgenic plants.

Localization of truncated GAD2 protein in the seeds

In order to confirm the accumulation of truncated GAD protein over-expressed by the $G l u B-1$ promoter in the endosperm, brown rice kernels $\left(\mathrm{T}_{2}\right.$ generation) were processed by milling machine, obtaining two fractions of milled rice and bran, respectively. Figure 3a shows results of western blot analysis of protein from rice 


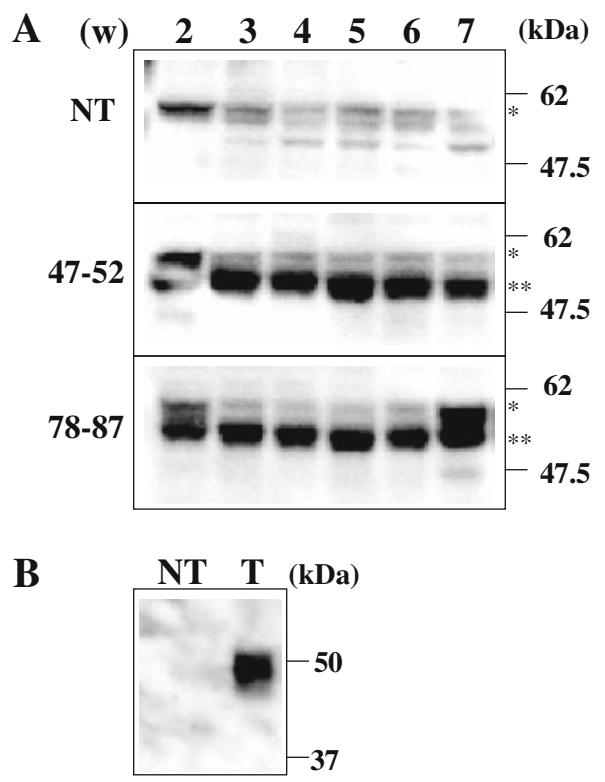

Fig. 2 Western blot analysis of rice seed proteins. a Soluble proteins were extracted from seeds after 2-7 weeks (w) of selfpollination. Total proteins $(10 \mu \mathrm{g})$ were loaded on $10 \%$ SDSPAGE, followed by electroblotting. Primary and secondary antibodies used were anti-GAD2 antibody and anti-rabbit IgG antibody conjugated with alkaline phosphatase (SIGMA), respectively. Positions of protein marker are shown on the right side. A single and double asterisks are corresponded to protein bands of GAD2 $(57 \mathrm{kDa})$ and GAD2 $\Delta \mathrm{C}(53 \mathrm{kDa})$, respectively. b Control experiment of western blot analysis. NT: calli from non-transformed rice, T: calli over-expressing $G A D 2 \triangle C$ described in Akama and Takaiwa (2007)

grain harvested at 1 month after flowering using an anti-GAD2 antibody: NT kernel did not give any positive band corresponding to the position of GAD2 protein, while line $47-52$ displayed a strong band in the polished fraction and a somewhat weaker band in the bran fraction. Although line $78-87$ was a relatively weaker band compared with line $47-52$, it could be detected. Figure $3 \mathrm{~b}$ shows protein localization in the seeds utilizing in situ western hybridization $(\mathrm{Qu}$ et al. 2003). Pre-immune serum did not show any signal in either NT or transgenic seeds, but anti-GAD2 antibody resulted in strong blue staining in the region of the endosperm from both lines (47-52 and 78-87), not in the germ. Taken together, over-expressed products were highly accumulated in the endosperm of the seeds. Moreover, enzyme analysis of milled rice powder from NTL and transgenic line 78-87 was done in the presence of $\mathrm{Ca}^{2+}$ and colmodulin at $\mathrm{pH} 5.5$ according as Akama and Takaiwa (2007). GAD enzyme activity of 78-87 was over six-fold higher than that of NTL (i.e., NTL, $6.0 \mathrm{pmol} / \mathrm{min} / \mathrm{mg} \mathrm{FW}$; 78-87, $40.3 \mathrm{pmol} / \mathrm{min} / \mathrm{mg} \mathrm{FW}$ ).

\section{Determination of GABA concentration}

As an initial screening, GABA analysis of the $\mathrm{T}_{1}$ seeds from 15 transgenic lines was performed to subsequently select two lines (i.e., 47-52 and 78-87) as described above. GABA content of the seed samples of $T_{2}, T_{3}$ and $T_{4}$ generations was assayed via an enzymatic procedure using GABase (SIGMA, St. Louis, USA), which was successfully applied previously in plants by Crawford et al. (1994). As shown in Table 1, GABA content of NT brown rice showed $0.05-0.16 \mu \mathrm{mol} / \mathrm{g} \mathrm{FW}$. In contrast, transgenic rice showed about ten times higher GABA concentration. Between the two lines, line 47-52 showed a higher GABA content than line 78-87. This tendency coincided with protein analysis shown in Fig. 3. In the case of the $\mathrm{T}_{4}$ generation, relatively higher GABA contents were observed in both lines.

Free amino acid and other components in the $\mathrm{T}_{4}$ generation

Milled rice grain samples from the $T_{4}$ generation were subjected to free amino acid analysis. Table 2 shows the results for one NT and two transgenic plants: average GABA values (nmol/g FW grain) were 52.3 for NTL, and about 1,445 and 687 for the transgenic lines. Surprisingly in the transgenics, an increase in not only GABA content, but also other free amino acid content was observed. The increase in the other amino acids analyzed seems to be closely related to the increase in GABA: the increase in free amino acids was roughly proportional to the GABA content increase in the two transgenic lines tested. In line 47-52, there was approximately a 28-fold increase in GABA and a 1.8 -fold increase in other protein amino acids when compared between total protein amino acids excluding GABA from NTL and line 47-52; in line 78-87, there was a 13 -fold increase in GABA and a 1.5-fold increase in other protein amino acids. Methionine (Met) and glycine (Gly) contents, in particular, increased markedly (about 9.5- and 7-fold, respectively), followed by leucine (Leu), lysine (Lys), and phenylalanine (Phe). This order was very similar among the two transgenic plants examined. 
A
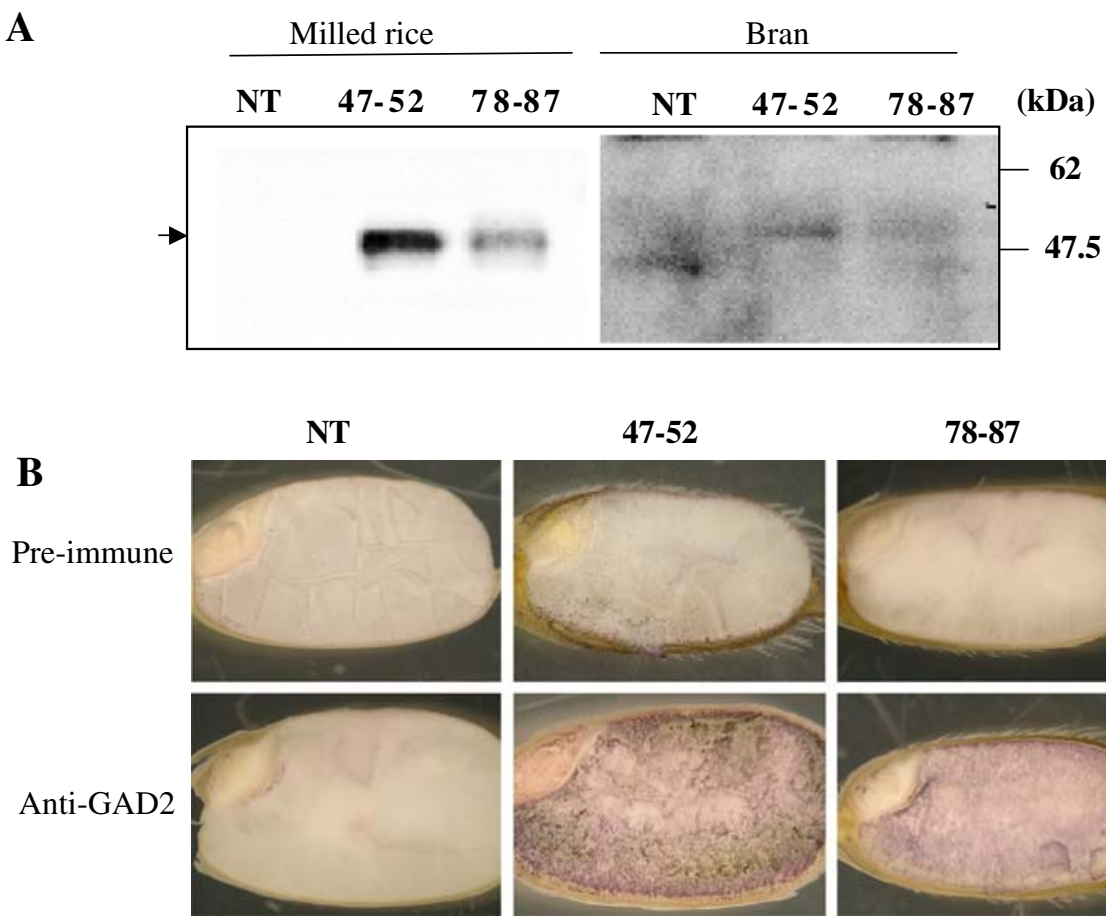

47-52

78-87
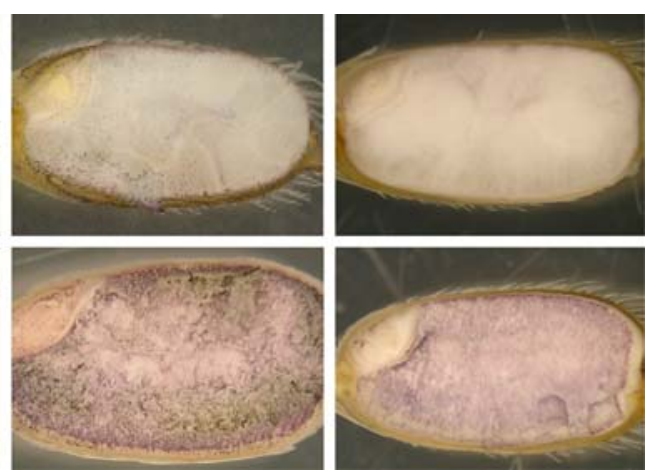

Fig. 3 Determination of protein localization. a Two different fractions (milled rice fraction or bran fraction) of rice kernels were subjected to western blot analysis. Arrow indicates the position of GAD $2 \Delta$ C protein. b In situ western localization of truncated GAD2 protein in transgenic rice seeds. Longitudinal sections of mature seeds were subsequently incubated with antibody: Pre-immune serum (Pre-immune) and anti-GAD2 antibody-containing serum (Anti-GAD2) were used as primary antibodies. After incubation with a secondary antibody (antiIgG antibody conjugated with alkaline phosphatase [AP]), section was immersed in Western Blue Stabilized Substrate for AP (Promega) to detect protein signal

Table 1 Determination of GABA content in rice seeds

\begin{tabular}{lllc}
\hline Plant generation & $\begin{array}{l}\text { NTL } \\
(\mu \mathrm{mol} / \mathrm{g} \mathrm{FW} \text { grain })\end{array}$ & $\begin{array}{l}47-52 \\
(\mu \mathrm{mol} / \mathrm{g} \mathrm{FW} \text { grain })\end{array}$ & $\begin{array}{l}78-87 \\
(\mu \mathrm{mol} / \mathrm{g} \mathrm{FW} \text { grain })\end{array}$ \\
\hline $\mathrm{T}_{2}$ & $0.05 \pm 0.04$ & $0.50 \pm 0.15$ & $0.56 \pm 0.14$ \\
$\mathrm{~T}_{3}$ & $0.07 \pm 0.08$ & $0.85 \pm 0.35$ & $0.42 \pm 0.22$ \\
$\mathrm{~T}_{4}$ & $0.16 \pm 0.04$ & $2.16 \pm 0.71$ & $1.12 \pm 0.77$ \\
\hline
\end{tabular}

Rice grain samples were subjected to the GABase reaction as described in "Materials and methods". For GABase assay, 12 grains from each plant $\mathrm{T}_{2}$ ( 5 for line 47-52, 9 for line 78-87), $\mathrm{T}_{3}$ (8 for both lines) and $\mathrm{T}_{4}$ (17 for 47-52, 18 for 78-87) were ground in fine powder. About $100 \mathrm{mg}$ of sample was used for isolation of free amino acids with TCA method. Data shows mean and SD of independent assay from three separate preparations of the samples. For NTL (non-transformed line), three independent plants of Nipponbare cultivated together with $\mathrm{T}_{2}$ to $\mathrm{T}_{4}$ plants were used for extraction of amino acids to determine GABA content similar to the transformed lines

In parallel, other components including basic compounds, minerals and vitamins were examined as summarized in supplemental Table S2. There was no significant difference in the amount of water, protein, lipid, total minerals and carbohydrate among the NT and GABA-enriched grains. Evaluating mineral content, sodium was about two times higher in NTL than both of the transgenic lines, while phosphorus, calcium, potassium and magnesium levels were relatively higher in transgenic rice.

Oral administration with milled $\mathrm{T}_{4}$ rice

In order to evaluate the functional effects of GABAenriched rice grains produced in this study, animal experiments were performed. Since GABA is mostly 
Table 2 Quantity of free amino acids in non-transformant (NT) and transformed seeds

\begin{tabular}{lccccc}
\hline Amino acid & NT $(\mathrm{nmol} / \mathrm{g} \mathrm{FW})$ & $47-52(\mathrm{nmol} / \mathrm{g} \mathrm{FW})$ & \multicolumn{3}{c}{$78-87(\mathrm{nmol} / \mathrm{g} \mathrm{FW})$} \\
\hline Asp & $1,148.8 \pm 484.5$ & $952.7 \pm 251.8$ & $(0.8)$ & $840.3 \pm 324.3$ & $(0.7)$ \\
Ser & $26.2 \pm 10.7$ & $114.0 \pm 22.3^{* *}$ & $(4.4)$ & $82.7 \pm 25.3^{*}$ & $(3.2)$ \\
Asn & $484.4 \pm 17.5$ & $992.6 \pm 146.4^{* *}$ & $(2.0)$ & $800.2 \pm 102.3^{* *}$ & $(1.7)$ \\
Glu & $974.5 \pm 30.8$ & $1,040.8 \pm 151.0$ & $(1.1)$ & $1,133.4 \pm 149.9$ & $(1.2)$ \\
Gln & $217.3 \pm 7.7$ & $275.9 \pm 42.2^{*}$ & $(1.3)$ & $166.0 \pm 24.6^{*}$ & $(0.8)$ \\
Gly & $37.1 \pm 12.4$ & $353.6 \pm 124.8^{* *}$ & $(9.5)$ & $266.2 \pm 26.2^{* *}$ & $(7.2)$ \\
Ala & $148.0 \pm 50.2$ & $942.5 \pm 246.1^{* *}$ & $(6.4)$ & $577.7 \pm 233.6^{*}$ & $(3.9)$ \\
Val & $48.4 \pm 2.6$ & $249.0 \pm 43.9^{* *}$ & $(5.1)$ & $178.1 \pm 25.1^{* *}$ & $(3.7)$ \\
Cys & $2.0 \pm 1.8$ & $4.1 \pm 3.0$ & $(2.1)$ & $2.5 \pm 3.1$ & $(1.3)$ \\
Met & $2.0 \pm 1.8$ & $21.0 \pm 16.6$ & $(10.6)$ & $19.2 \pm 16.1$ & $(9.7)$ \\
Ile & $19.8 \pm 1.8$ & $112.2 \pm 16.3^{* *}$ & $(5.7)$ & $79.1 \pm 9.4^{* *}$ & $(4.0)$ \\
Leu & $18.0 \pm 1.8$ & $156.6 \pm 23.6^{* *}$ & $(8.7)$ & $116.4 \pm 11.8^{* *}$ & $(6.5)$ \\
Tyr & $19.3 \pm 0.6$ & $87.4 \pm 11.9^{* *}$ & $(4.5)$ & $65.0 \pm 7.3^{* *}$ & $(3.4)$ \\
Phe & $12.9 \pm 2.5$ & $87.9 \pm 9.6^{* *}$ & $(6.8)$ & $58.9 \pm 4.0^{* *}$ & $(4.6)$ \\
GABA & $52.3 \pm 2.9$ & $1,445.2 \pm 196.9^{* *}$ & $(27.7)$ & $687.2 \pm 63.5^{* *}$ & $(13.2)$ \\
His & $30.8 \pm 1.5$ & $63.3 \pm 10.5^{* *}$ & $(2.1)$ & $47.1 \pm 5.8^{* *}$ & $(1.5)$ \\
Lys & $15.0 \pm 5.8$ & $125.8 \pm 14.7 * *$ & $(8.4)$ & $89.2 \pm 3.9^{* *}$ & $(5.9)$ \\
Arg & $69.2 \pm 3.0$ & $209.7 \pm 31.5^{* *}$ & $(3.0)$ & $171.6 \pm 26.7^{* *}$ & $(2.5)$ \\
Pro & $72.9 \pm 51.5$ & $393.8 \pm 138.3^{* *}$ & $(5.4)$ & $259.4 \pm 81.3^{* *}$ & $(3.6)$ \\
Total & $3,398.9 \pm 691.4$ & $7,628.2 \pm 1,501.1^{* *}$ & $(2.2)$ & $5,640.3 \pm 1,144.2^{* *}$ & $(1.7)$ \\
Total (-GABA) & $3,346.6 \pm 688.5$ & $6,183.0 \pm 1,304.2^{* *}$ & $(1.8)$ & $4,953.1 \pm 1,080.7 * *$ & $(1.5)$ \\
\hline
\end{tabular}

expected to lower blood pressure in mammals, we used SHRs, which are one of the most commonly used models for the study of hypertension and cardiovascular disease (Okamoto and Aoki 1963). We prepared four different GABA-containing samples that were administered to rats orally. After the rice grains were processed to powder, they were suspended in distilled water. Samples were prepared as follows: NT rice: $0.016-\mathrm{mg}$ dose of $\mathrm{GABA} / \mathrm{kg}$ rat body weight (BW); GABA-enriched rice grains: low and high doses corresponding to $0.1 \mathrm{mg}$ and $0.5 \mathrm{mg}$ doses of GABA $/ \mathrm{kg}$ rat BW, respectively. As a GABA control, $0.5 \mathrm{mg}$ GABA reagent (SIGMA) was also used. After 2 weeks of acclimation, SHRs were divided into four groups $(n=6)$ as described above to begin the oral administration, while three groups were formed for WKY. In the case of SHRs, dosages were administered for 6 weeks. In all experiments of an oral administration described above in three different kinds of rats, there was no significant difference of weight-change during 6 weeks (data not shown). As shown in Fig. $4 \mathrm{a}$, after 4 weeks, rat groups (SHR) fed with rice containing higher concentrations of GABA ( $0.5 \mathrm{mg}$ GABA) showed approximately a $20 \mathrm{mmHg}$ decrease in blood pressure than those fed NT. This tendency continued 2 weeks further. Interestingly, GABA rice $(0.1 \mathrm{mg})$ and GABA reagent $(0.5 \mathrm{mg})$ showed a relatively weak effect on blood pressure, except at 4 weeks' dosing with GABA reagent $(0.5 \mathrm{mg})$; between 4 and 6 weeks, there was no significant effect on blood pressure. We next tested metabolic syndrome rats, (SHR/cp), because this rat has received much attention as a model for the study of life-style related diseases. Similar oral administrations as described above were carried out in the SHR/cps. As shown in Fig. $4 \mathrm{~b}$, GABA rice $(0.5 \mathrm{mg})$ displayed antihypertensive effects, while the other doses did not show any sustained blood pressure lowering effects. Finally, we used normotensive rats (WKY) to examine whether GABA-enriched rice affects blood pressure in normal rats. Figure $4 \mathrm{c}$ indicated no significant change in blood pressure among three different samples (NT, GABA rice [0.5 mg] and GABA reagent $[0.5 \mathrm{mg}])$. Taken together, these results indicate that the administration of $0.5 \mathrm{mg}$ GABA-containing rice/ $\mathrm{kg}$ rat $\mathrm{BW}$ resulted in a reproducible lowering effect on blood pressure of 
A

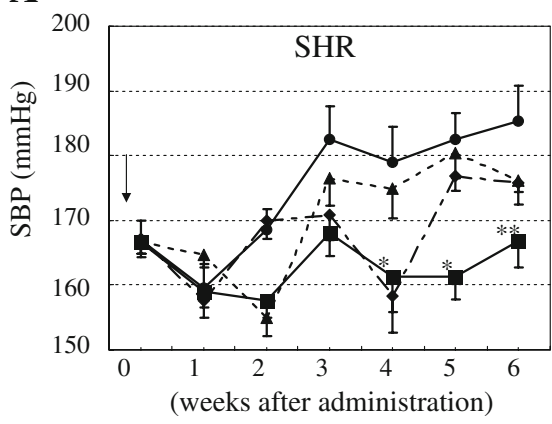

C

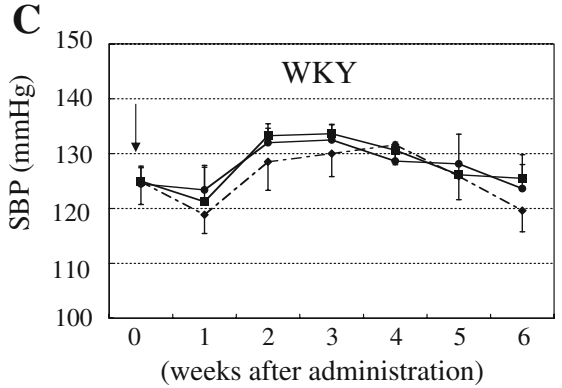

Fig. 4 Oral administration of GABA-enriched rice in rats. Effect of polished rice on systolic blood pressure (SBP) in spontaneously hypertensive rat (SHR/NCrlCrlj) (a), metabolic syndrome rat (SHR/NDmcr-cp) (b), and normotensive WistarKyoto rats (WKY) (c). Dosage of GABA to SHR per daily administration was $0.5 \mathrm{mg} / \mathrm{kg}$ body weight (BW) ( $\mathbf{\square}$ : GABArice $0.5 \mathrm{mg})$ and $0.1 \mathrm{mg} / \mathrm{kg} \mathrm{BW}(\boldsymbol{\Lambda}$ : GABA-rice $0.1 \mathrm{mg})$ in

about $20 \mathrm{~mm} \mathrm{Hg}$ in both kinds of SHRs, but not in WKY.

\section{Discussion}

In this study we established transgenic rice plants that displayed higher concentrations of GABA in the endosperm of the seeds in order to evaluate the effect of orally administered rice grains in hypertensive rats. In our previous reports (Akama and Takaiwa 2007), $G A D 2 \triangle C$ driven by $35 \mathrm{~S}$ promoter showed an extremely high level of GABA in the vegetative tissues. However, due to its high accumulation, plants showed aberrant phenotype and did not reach the reproductive stage. In the present study, the mutant gene construct was controlled by rice GluB-1 promoter, which is well characterized in seed-specific expression (Takaiwa et al. 1991; Washida et al. 1999). During the vegetative stage, there was no difference in plant growth and phenotypes between
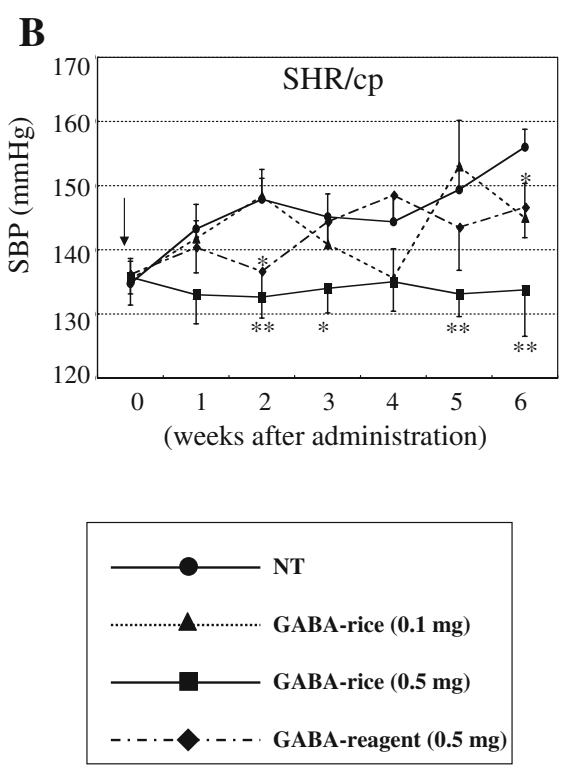

polished rice from transformed rice plants, respectively, $0.016 \mathrm{mg} / \mathrm{kg} \mathrm{BW}(\mathbf{N T})$ in non-transformed rice plants and $0.5 \mathrm{mg}$ GABA reagent $/ \mathrm{kg}$ BW $(\diamond:$ GABA-reagent $0.5 \mathrm{mg}$ ). Each data-point represents the mean \pm SE. Single and double asterisks indicate $P<0.05$ versus NT and $P<0.01$ versus NT, respectively

transgenics and NT. Even during the seed maturation stage, analyzing several parameters for rice yield (Table S1), there was no significant difference between the number and weight of seeds per plants, and sterility. This indicates that tightly regulated GluB-1 promoter and GABA accumulation did not affect the seed-maturation process in rice plants. Over-expression of the introduced gene's protein products in edible parts of the seeds was confirmed both with western blot and in situ histochemical analyses (Fig. 3). Likewise there have been many prior reports of the successful over-expression of GluB-1-controlled foreign genes in the rice endosperm (Takagi et al. 2005; Wakasa et al. 2006b).

GABase analysis of the transgenic seeds indicated about $0.5-2.2 \mu \mathrm{mol}$ of GABA per gram grain, equivalent to 5-22 $\mathrm{mg}$ of GABA per $100 \mathrm{~g}$ grain in three successive generations (Table 1). Interestingly, the increasing GABA level in these successive generations from both non-transformed and transformed lines was observed. This increase in GABA level 
might be influenced by different growth conditions (growth-chamber and greenhouse in $\mathrm{T}_{1}$ or $\mathrm{T}_{2}$ and $\mathrm{T}_{3}$, respectively), although further analysis in the same natural conditions must be required. After milling the brown rice, the GABA content of polished rice was measured at $\sim 0.7$ and $1.45 \mu \mathrm{mol} / \mathrm{g}$ (from 687.2 to $1,445.2 \mathrm{nmol} / \mathrm{g}$ in Table 2), with most of the GABA content remaining. Although several groups have achieved increased GABA levels in the vegetative tissues of tobacco using a transgenic approach (Baum et al. 1996; MacLean et al. 2003), as far as we know this is the first report of extremely high levels of GABA in grains, especially in milled rice that is an ordinary form of the diet for human.

Unexpectedly, an increase in not only GABA content, but also other free amino acid content was observed in the transgenic rice (Table 2). The increase in other amino acids analyzed seems to be closely related to that in GABA: the increase in free amino acids was roughly proportional to the GABA content in two different transgenic lines tested. With the exception of aspartate (Asp), glutamate (Glu) and glutamine (Gln), other protein amino acids also accumulated in high levels. In our previous study in which $G A D 2 \triangle C$ was over-expressed in callus cells, we found that GABA content increased, but that the remaining protein amino acids were present at almost the same levels or lower levels than in NT calli (Akama and Takaiwa 2007). These findings show that the accumulation of GABA in rice grains, acting as sink organs, may differentially influence the composition of the amino acid pool, because both grains and calli also accumulated a large amount of GABA as well. Very recently, Akihiro et al. (2008) reported that during fruit development in tomatoes not only GAD but also $\alpha$-ketoglutarate-dependent GABA transaminase (GABA-TK) activity plays a critical role in the accumulation of GABA in tomato fruit. Kisaka et al. (2006) have developed transgenic tomato fruits where $G A D$ expression was antisense suppressed. Amino acid analysis of the fruit revealed an increase not only in Glu, but also in other free amino acids, in three out of four transgenic lines. Taking these reports into account, although it has remained unclear regarding GABA-TK activity in rice seeds, a combination of the high activity of truncated GAD2 and putative GABATK activity might result in the rapid turnover of Glu as an amino residue donor to a wide range of amino acids, i.e., sufficient supply of 2-oxoglutarate and other 2-oxo acids (Forde and Lea 2007). On the other hand, it was shown that over-expression of the transgene encoding $\alpha$ subunit of rice anthranilate synthase (AS) results not only in a marked increase in tryptophan (Trp) than is expected, but also in most of the other protein amino acid content as well (Wakasa et al. 2006a). It was speculated that Trp accumulation in rice seeds increases the transcription of genes that are involved in amino acid synthesis. It has also been indicated that Asp kinase 2 and Dof 1 transcription factor are critical for amino acid synthesis or nitrogen assimilation (Wang et al. 2001; Yanagisawa et al. 2004). On the basis of these findings, it would be tempting to speculate that GABA plays a role in regulating homeostasis of amino acid metabolism via control of key factor(s), especially in seeds. To clarify these points, further analyses of transgenic lines, i.e., assessing carbon and nitrogen assimilation and amino acid metabolism in concert with the expression of genes involved in these metabolic pathways, is required.

We demonstrated that SHRs administered a $0.5-\mathrm{mg}$ dose of GABA-enriched rice grain (per $\mathrm{kg} \mathrm{BW}$ ) resulted in about a $20-\mathrm{mmHg}$ antihypertensive effect of systolic blood pressure (SBP) both in SHR and SHR/cp. However, neither the lower dose $(0.1 \mathrm{mg}$ GABA) nor $0.5 \mathrm{mg}$ GABA reagent showed a significant SBP-lowering effect. On the other hand, Hayakawa et al. (2004) reported that $0.5 \mathrm{mg}$ GABA reagent $/ \mathrm{kg} \mathrm{BW}$ in SHR has a lowering effect on BP at 4-8 h after oral administration and also at 4 weeks of administration, although we cannot clearly explain the contradiction among the two experiments. Rice grains established in this study contain not only higher amount of GABA but also increase in most of protein amino acids, which may be related to induce blood pressure lowering effect (discussed in detail in below). Nevertheless, it should be noted that a decrease in SBP did not occur in WKY. It has already been shown that GABA has no lowering effect on BP in the case of humans with normal BP (Tsuchida et al. 2003). Until now, there have been many reports on the blood pressure lowering effect of GABA-containing foods (rice germ soaked in water, anaerobically treated tea, and fermented milk product) in which GABA accumulation showed about a $10-15 \%$ reduction in SBP compared with the control group of SHRs (Saikusa et al. 1994; Abe et al. 1995; Hayakawa et al. 2004). Because GABA poorly crosses the blood-brain 
barrier (Kuriyama and Sze 1971), it has been speculated that exogenous GABA acts within peripheral tissues such as blood vessel (Manzini et al. 1985). In order to explore the mechanism of GABA-mediated suppression of BP, we evaluated the level of ACE, nitronic oxide (NOx) and aldestrone in plasma, which are all critical parameters in blood pressure regulation. However, these were not changed significantly in the rats fed with GABA-enriched rice grains, suggesting an antihypertensive effect observed in this study might not be explained based on these parameters. Although we can only speculate to what extent GABA brings about a BP lowering effect, it is highly possible that a combination of GABA with unknown factors could induce anti-hypertensive effects in this study. It has been reported that amino acids such as arginine (Arg) and nicotianamine have an antihypertensive effect via vasodilation and ACE inhibition, respectively (Costa et al. 1998; Hayashi and Kimoto 2007). A recent study has also disclosed that amino acids have an unexpected new role in mammals, i.e., as a putative trigger for insulin secretion (e.g., Newsholme et al. 2005). Because basic components, vitamins, and minerals (except for sodium) are almost the same between Nipponbare and GABA-enriched rice, the transgenic rice established in this study possess not only GABA but also many kinds of amino acids, implying one or several amino acids could cooperatively interact with GABA, inducing an antihypertensive effect in SHR with long-range oral administration. It would be interesting to evaluate which amino acids actually relate to the reduction of SBP in order to evaluate its independent role in decreasing SBP in SHRs as well as mechanisms that are involved.

In conclusion, we established GABA-enriched rice in this study. Compared with SHRs that were administered common rice, SHRs that were fed GABA-enriched rice showed a significant effect in the lowering of BP. Therefore, transgenic rice lines established in this study are likewise expected to protect humans from diseases that occur due to high BP. Besides, the latest report indicates that metabolism of GABA and $\gamma$-hydorxybutyric acid (GHB) which is known as a drug of abuse, are tightly linked even in plants (Ludewig et al. 2008). Although there has been no clear report on health problem of GABAenriched foods from plants by a human consumption so far, it should be considered to determine the level of GHB in the GABA enriched rice developed in this study for future practical use.

Acknowledgments This research was supported by grants for Functional Analysis of Genes Relevant to Agriculturally Important Traits in the Rice Genome from the Ministry of Agriculture, Forestry and Fisheries of Japan (Green Technology Project IP-2004).

Open Access This article is distributed under the terms of the Creative Commons Attribution Noncommercial License which permits any noncommercial use, distribution, and reproduction in any medium, provided the original author(s) and source are credited.

\section{References}

Abe Y, Umemura S, Sugimoto K, Hirawa N, Kato Y, Yokoyama N, Yokoyama T, Iwai J, Ishii M (1995) Effect of green tea rich in gamma-aminobutyric acid on blood pressure of Dahl salt-sensitive rats. Am J Hypertens 8:7479. doi:10.1016/0895-7061(94)00141-W

Akama K, Takaiwa F (2007) C-Terminal extension of rice glutamate decarboxylase (OsGAD2) functions as an autoinhibitory domain and overexpression of a truncated mutant results in the accumulation of extremely high levels of GABA in plant cells. J Exp Bot 58:2699-2707. doi:10.1093/jxb/erm120

Akama K, Akihiro T, Kitagawa M, Takaiwa F (2001) Rice (Oryza sativa) contains a novel isoform of glutamate decarboxylase that lacks an authentic calmodulin-binding domain at the C-terminus. Biochim Biophys Acta 1522: 143-150

Akihiro T, Koike S, Tani R, Tominaga T, Watanabe S, Iijima Y, Aoki K, Shibata D, Ashihara H, Matsukura C, Akama K, Fujimura T, Ezura H (2008) Biochemical mechanism on GABA accumulation during fruit development in tomato. Plant Cell Physiol 49:1378-1389. doi:10.1093/ pcp/pcn 113

Baum G, Lev-Yadun S, Fridmann Y, Arazi T, Katsnelson H, Zik M, Fromm H (1996) Calmodulin binding to glutamate decarboxylase is required for regulation of glutamate and GABA metabolism and normal development in plants. EMBO J 15:2988-2996

Bouché N, Fromm H (2004) GABA in plants: just a metabolite? Trends Plant Sci 9:110-115. doi:10.1016/j.tplants. 2004.01.006

Costa MA, Balaszczuk AM, Dominguez A, Catanzaro O, Arranz C (1998) Effects of L-NAME and L-Arg on arterial blood pressure in normotensive and hypertensive streptozotocin diabetic rats. Acta Physiol Pharmacol Ther Latinoam 48:59-63

Crawford LA, Bown AW, Breitkreuz KE, Guinel FC (1994) The synthesis of [gamma]-aminobutyric acid in response to treatments reducing cytosolic $\mathrm{pH}$. Plant Physiol 104: $865-871$

Curtis DR, Johston GAR (1974) Amino acids transmitters in the mammalian central nervous system. Ergeb Physiol 69:97-188 
Forde BG, Lea PJ (2007) Glutamate in plants: metabolism, regulation, and signalling. J Exp Bot 58:2339-2358. doi: 10.1093/jxb/erm 121

Graham LT Jr, Aprison MH (1966) Fluorometric determination of aspartate, glutamate, and gamma-aminobutyrate in nerve tissue using enzymic methods. Anal Biochem 15:487-497. doi:10.1016/0003-2697(66)90110-2

Hayakawa K, Kimura M, Kasaha K, Matsumoto K, Sansawa H, Yamori Y (2004) Effect of a gamma-aminobutyric acid-enriched dairy product on the blood pressure of spontaneously hypertensive and normotensive WistarKyoto rats. Br J Nutr 92:411-417. doi:10.1079/BJN20041 221

Hayashi A, Kimoto K (2007) Nicotianamine preferentially inhibits angiotensin I-converting enzyme. J Nutr Sci Vitaminol (Tokyo) 53:331-336. doi:10.3177/jnsv.53.331

Hiei Y, Ohta S, Komari T, Kumashiro T (1994) Efficient transformation of rice (Oryza sativa L.) mediated by Agrobacterium and sequence analysis of the boundaries of the T-DNA. Plant J 6:271-282. doi:10.1046/j.1365-313X. 1994.6020271.x

Hong F, Ming L, Yi S, Zhanxia L, Yongquan W, Chi L (2008) The antihypertensive effect of peptides: a novel alternative to drugs? Peptides 29:1062-1071. doi:10.1016/ j.peptides.2008.02.005

Hood EE, Belvin SB, Melchers LS, Hoekema A (1993) New Agrobacterium helper plasmids for gene transfer to plants. Transgenic Res 2:208-218. doi:10.1007/BF01977351

Kearney PM, Whelton M, Reynolds K, Muntner P, Whelton PK, He J (2005) Global burden of hypertension: analysis of worldwide data. Lancet 365:217-223

Kisaka H, Kida T, Miwa T (2006) Antisense suppression of glutamate decarboxylase in tomato (Lycopersicon esculentum L.) results in accumulation of glutamate in transgenic tomato fruits. Plant Biotechnol 23:267-274

Kuriyama M, Sze PY (1971) Blood-brain barrier to ${ }^{3} \mathrm{H}-\gamma-$ aminobutyric acid in normal and amino oxyacetic acidtreated animals. Neuropharmacology 10:103-108. doi: 10.1016/0028-3908(71)90013-X

Leventhal AG, Wang Y, Pu M, Zhou Y, Ma Y (2003) GABA and its agonists improved visual cortical function in senescent monkeys. Science 300:812-815. doi:10.1126/ science. 1082874

Ludewig F, Huser A, Fromm H, Beauclair L, Bouché N (2008) Mutants of GABA transaminase (POP2) suppress the severe phenotype of succinic semialdehyde dehydrogenase (ssadh) mutants in Arabidopsis. PLoS ONE 3:1-11. doi:10.1371/journal.pone.0003383

MacLean MDYD, Deschene A, Van Cauwenberghe OR, Makhmoudova A, Potter JW, Bown AW, Shelp BJ (2003) Overexpression of glutamate decarboxylase in transgenic tobacco plants confers resistance to the northern root-knot nematode. Mol Breed 11:277-285. doi:10.1023/A:1023 483106582

Manzini S, Maggi CA, Meli A (1985) Inhibitory effect of GABA on sympathetic neurotransmission in rabbit ear artery. Arch Int Pharmacodyn 273:100-109

Murashige T, Skoog F (1962) A revised medium for rapid growth and bioassays with tobacco tissue cultures. Physiol Plant 15:473-497. doi:10.1111/j.1399-3054.1962.tb08052.x
Murray MG, Thompson WF (1980) Rapid isolation of high molecular weight plant DNA. Nucleic Acids Res 8:43214325. doi:10.1093/nar/8.19.4321

Newsholme P, Brennan L, Rubi B, Maechler P (2005) New insights into amino acid metabolism, beta-cell function and diabetes. Clin Sci (Lond) 108:185-194. doi:10.1042/ CS20040290

Okamoto K, Aoki K (1963) Development of a strain of spontaneously hypertensive rats. Jpn Circ J 27:282-293

Project IRGS (2005) The map-based sequence of the rice genome. Nature 436:793-800. doi:10.1038/nature03895

Qu LQ, Tada Y, Takaiwa F (2003) In situ western hybridization: a new, highly sensitive technique to detect foreign and endogenous protein distribution in rice seeds. Plant Cell Rep 22:282-285. doi:10.1007/s00299-003-0683-9

Saikusa T, Horino T, Mori Y (1994) Accumulation of $\gamma$-aminobutyric acid (Gaba) in the rice germ during water soaking. Biosci Biotechnol Biochem 58:2291-2292

Takagi H, Hiroi T, Yang L, Tada Y, Yuki Y, Takamura K, Ishimitsu R, Kawauchi H, Kiyono H, Takaiwa F (2005) A rice-based edible vaccine expressing multiple $\mathrm{T}$ cell epitopes induces oral tolerance for inhibition of Th2-mediated IgE responses. Proc Natl Acad Sci USA 102:1752517530. doi:10.1073/pnas.0503428102

Takahashi H, Tiba M, Iino M, Takayasu T (1955) The effect of $\gamma$-aminobutyric acid on blood pressure. Jpn J Physiol 5: 334-341

Takaiwa F, Oono K, Wing D, Kato A (1991) Sequence of three members and expression of a new major subfamily of glutelin genes from rice. Plant Mol Biol 17:875-885. doi: 10.1007/BF00037068

Tsuchida T, Mashiko K, Yamada K, Hiratsuka H, Shimada T, Itagaki Y, Fujinuma H, Samejima K, Nakamura T, Hasegawa T, Matsubayashi T (2003) Clinical study of $\gamma$-aminobutyric acid-rich Chlorella for subjects with highnormal blood and mild hypertension. J Jpn Soc Nutr Food Sci 56:97-102 (text in Japanese with English abstract)

Wakasa K, Hasegawa H, Nemoto H, Matsuda F, Miyazawa H, Tozawa Y, Morino K, Komatsu A, Yamada T, Terakawa T, Miyagawa H (2006a) High-level tryptophan accumulation in seeds of transgenic rice and its limited effects on agronomic traits and seed metabolite profile. J Exp Bot 57:3069-3078. doi:10.1093/jxb/er1068

Wakasa Y, Yasuda H, Takaiwa F (2006b) High accumulation of bioactive peptide in transgenic rice seeds by expression of introduced multiple genes. Plant Biotechnol J 4:499-510

Wang X, Stumpf DK, Larkins BA (2001) Aspartate kinase 2. A candidate gene of a quantitative trait locus influencing free amino acid content in maize endosperm. Plant Physiol 125:1778-1787. doi:10.1104/pp.125.4.1778

Washida H, Wu CY, Suzuki A, Yamanouchi U, Akihama T, Harada K, Takaiwa F (1999) Identification of cis-regulatory elements required for endosperm expression of the rice storage protein glutelin gene GluB-1. Plant Mol Biol 40:1-12. doi:10.1023/A:1026459229671

Yanagisawa S, Akiyama A, Kisaka H, Uchimiya H, Miwa T (2004) Metabolic engineering with Dof1 transcription factor in plants: improved nitrogen assimilation and growth under low-nitrogen conditions. Proc Natl Acad Sci USA 101:7833-7838. doi:10.1073/pnas.0402267101 